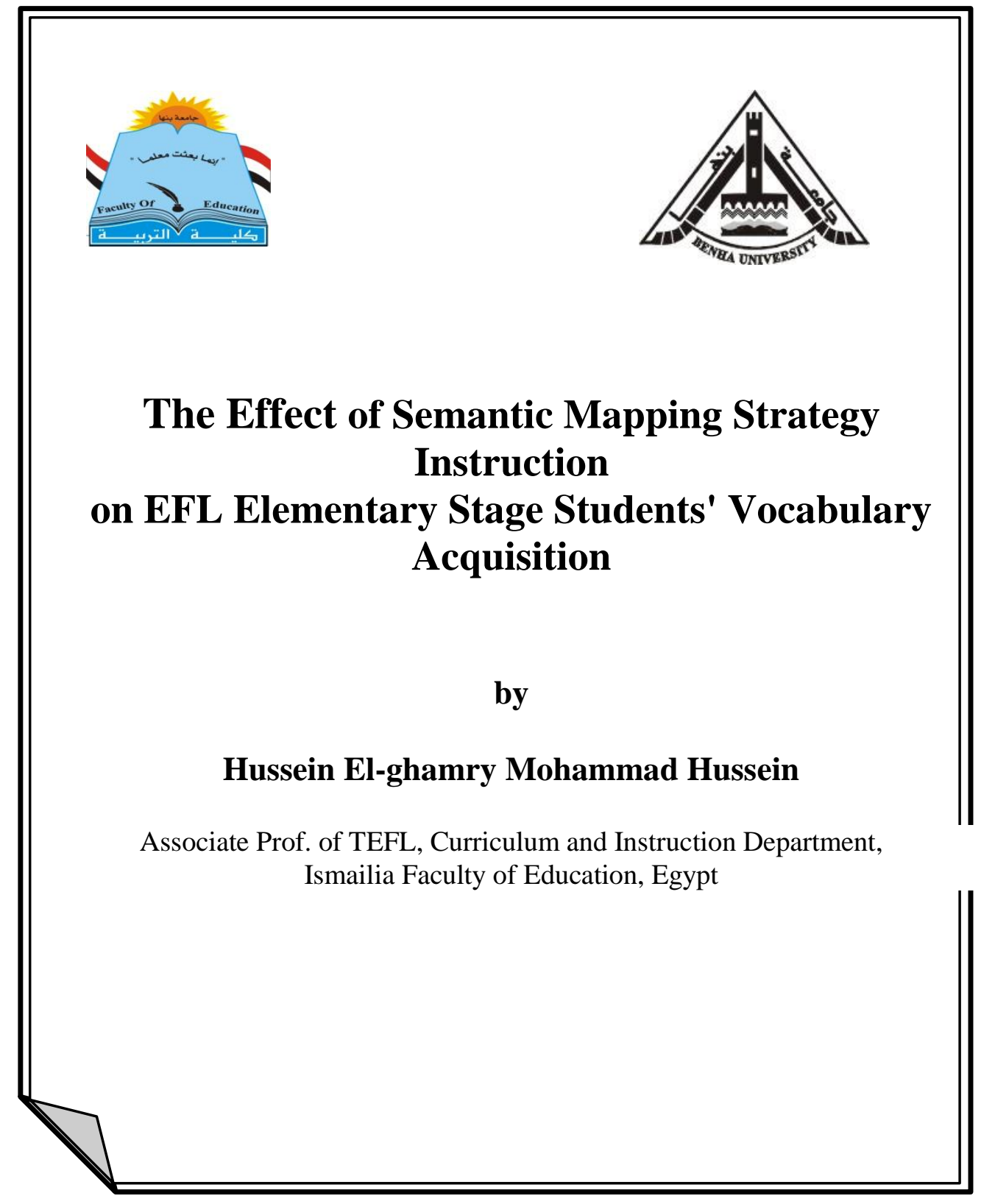




\section{The Effect of Semantic Mapping Strategy Instruction on EFL Elementary Stage Students' Vocabulary Acquisition}

\section{By}

\section{Hussein El-ghamry Mohammad Hussein}

\section{Abstract}

The present study sought to investigate the effect of semantic mapping strategy instruction on EFL elementary stage students' vocabulary acquisition. The study sample comprised fifty-two sixthgrade elementary students at Sufan Primary School in Bisha, K.S.A. The participants were randomly assigned either to the control group $(\mathrm{N}=26)$ or the experimental group $(\mathrm{N}=26)$. Both groups were pre-post tested using a vocabulary test prepared by the researcher. Then, the experimental group was taught the course-book 'WE CAN' supplemented with semantic mapping strategy instruction whereas the control group was taught the same course-book in the traditional method. Two hypotheses were formulated and tested. A T-test was used in the statistical analysis of the collected data. Results revealed that semantic mapping strategy instruction is effective in enhancing vocabulary acquisition among the participants in the experimental group. In addition, compared to traditional instruction, semantic mapping strategy instruction was more effective in developing the participants' vocabulary acquisition. These results substantiate the importance of implementing semantic mapping strategy instruction in EFL classrooms as it helps learners to move vocabulary knowledge to the long-term memory for storage purposes and retrieve it from longterm as needed for use. 


\section{Introduction}

Vocabulary is one of the most important language constituents without which neither language acquisition nor production is possible. Word knowledge is an essential component of EFL/ESL learners' communicative competence; it plays a pivotal role in language comprehension and production. In addition, vocabulary is the basic means for language learning as it represents the building blocks of language which enable EFL/ESL learners to convey their intended message.

The importance of vocabulary knowledge in EFL/ESL language learning has been recently emphasized by theorists and researchers in the field (Barcroft, 2004; Bromley, 2007; Ghazal, 2007; Hansen, 2009; Abdollahzadeh \& Amiri-Vardani, 2009; Zahedi \& Abdi, (2012) and Afrin,2014). These studies found positive correlation between vocabulary acquisition and language performance. For example, while Barcroft (2004: 201) identified three reasons highlighting the importance of vocabulary in language acquisition: (1) the relationship between vocabulary and learners' ability to communicate, (2) learners' perceptions about the importance of vocabulary, and (3) the central role of vocabulary acquisition in enhancing learners' grammatical competence. Bromley also (2007: 528) concluded that "vocabulary is a principal contributor to comprehension, fluency, and achievement".

Given that vocabulary plays a vital role in language learning, vocabulary acquisition is a complex and challenging task to EFL learners as it involves much more than learning word meanings; it also involves learning word pronunciation, forms and use. In addition, not only do EFL/ESL learners need to know meanings of the target vocabulary items, but they should also know how and when to use them in context. Thus, as indicated by (Al-Jarf, 2006:2),"vocabulary teaching and learning constitute a major problem for EFL instructors and students". One way to mitigate the burden is to equip learners with suitable vocabulary learning strategies and encourage them to apply these strategies as efficiently as possible in real situations. Such strategies help learners become independent and self- directed. Accordingly, they assume responsibility for their own learning and gradually gain confidence which ensures better 
vocabulary acquisition.

Semantic mapping is one of the vocabulary learning strategies which empower EFL/ESL to effectively learn vocabulary independently. It involves drawing graphic tools (a graph, diagram ...etc.) which display word/concept relationships. It enhances word learning and retention as it enables learners to incorporate new words into what they previously know; it guides learners to use the words and information in their word and concept repertoire to associate meanings with the new words. This leads to deeper vocabulary learning and thus longer retention of the target vocabulary items. Previous research on vocabulary reveals a significant improvement in vocabulary acquisition whenever semantic maps were used (Keshavarz et al., 2006:149; Abdollahzadeh \& Amiri-Vardani ,2009:1; Baleghizadeh \& Yousefpoori ,2011:15 ; Nilforoushan , 2012:165;Abbasian \& Arianezhad , 2013: 139; Jang, 2014:25; Afrin, 2014:65 and Avrianti ,2015:95).

\section{Context of the Problem:}

As the field of English language teaching has changed worldwide in the last decade, changes were also observed in the Kingdom of Saudi Arabia. New English courses have been designed and implemented as a compulsory subject for sixth grade elementary students eight years ago and for fourth and fifth grade students two years ago. However, as revealed by Alamri (2008:81-82) pupils, teachers and supervisors have complained that sixth grade English course-book (English for Saudi Arabia) is teacher centered. It does not provide ample opportunities for students to participate in class activities. It emphasizes rote learning and memorization which do not develop students' communicative competence. Although, the Ministry of Education in KSA developed a new English course (WE CAN) in 2013, Aljuhaish (2015:33) revealed that a plethora of learners, teachers and supervisors stated that the book is too vocabulary-based and beyond the level of the learners. He concluded also that there is disagreement between the course contents and the time allotted for the English lessons.

Moreover, the Saudi context is a typical example of the traditional 
grammar-translation method which focuses on learning grammatical rules then applying them by means of translation both into and from the mother tongue (Elyas \& Picard, 2010:136). Thus, as concluded by Alshammari, 2011:95) and Al-Nasser (2015:1613) and Alharbi (2015:3), Alharbi (2015:106) Mudawi (2015:51)), Saudi teachers use Arabic in English classes as a means of communication and explanation. Accordingly, the adopted teaching method (The Grammar-Translation Method) does not create real-life situations that provide students with ample opportunities for full language exposure and use (Al-Nasser ,2015:1613).

Accordingly, since the English course book prescribed to sixth grade elementary students is too vocabulary-based and beyond the level of the learners as revealed by Aljuhaish (2015:33), good vocabulary instruction is the most powerful means for enhancing students' vocabulary acquisition. Semantic mapping is an effective method which has proved to be felicitous in enhancing EFL/ESL learners' vocabulary acquisition (Keshavarz et al., 2006:149;Abdollahzadeh \& Amiri-Vardani , 2009:1; Baleghizadeh \& Yousefpoori ,2011:15 ; Nilforoushan , 2012:165;Abbasian \& Arianezhad , 2013: 139; Jang, 2014:25 and Afrin, 2014:65).

\section{Statement of the Problem}

Although the EFL course prescribed to the sixth grade elementary students in Kingdom of Saudi Arabia was developed in 2008 (English for Saudi Arabia) and 2013 (WE CAN), EFL teachers and supervisors have complained that 'English for Saudi Arabia' was teacher-centered and 'WE CAN' was too vocabulary-based. Accordingly, they do not provide ample opportunities for students to participate in class activities. In addition, they encourage rote learning and memorization which do not develop students' communicative competence. In addition, Aljuhaish (2015:33) concluded that the newly developed course (WE CAN) is too vocabulary-based and beyond the level of the learners. Furthermore, there is disagreement between the course contents and the time allotted for the English lessons Aljuhaish (2015:33).

Moreover, Alshammari (2011:95), Al-Nasser (2015:1613), Alharbi 
(2015:3), Alharbi (2015:106), Mudawi (2015:51) and AlMalihi (2015:86) revealed that Saudi EFL teachers adopt the grammar-translation method which encourages learners to memorize grammatical rules and vocabulary lists for use in translation exercises. In addition, Al-Nasser (2015:1613) concluded that most of those teachers were not fully ready to teach at this level since more than half of them did not receive enough pre-service nor in-service training on how to teach EFL to young learners. So, they use Arabic in English classes as a means of communication and explanation. Therefore, the adopted teaching method (The grammartranslation method) does not create real-life situations in which learners use English for real communication.

Accordingly, being a supervisor of college trainees for eight years in primary, schools around Bisha, researcher observed that adopting the grammar translation method led teachers to depend on translation as the only technique for presenting vocabulary. In addition, students achieve little in terms of language proficiency (Alqahtani , 2009:3; Khan, 2011: 1248;Alresheed, 2012:15 and Alhaisoni, 2013:114). Learners are faced with difficulty in speaking English, due to their inability to understand meanings of words which are learned on lists, not in a context.

Since the English course book prescribed to sixth grade elementary students (WE CAN) is too vocabulary-based and beyond the level of the learners (Aljuhaish, 2015:33), good vocabulary instruction is the most powerful means for enhancing students' vocabulary acquisition.

The present study attempted to improve sixth grade elementary students' vocabulary acquisition by examining the effect of semantic mapping strategy instruction on their vocabulary acquisition. To this end two research questions were addressed:

1. What is the effect of semantic mapping strategy instruction on sixth grade elementary students' vocabulary acquisition?

2. Which is more effective, the traditional method or semantic mapping strategy instruction, in enhancing students' vocabulary acquisition? 


\section{Purpose of the Study}

The primary focus of this study was to investigate the effect of applying semantic mapping strategy instruction on sixth grade elementary students' vocabulary acquisition. A secondary purpose was to provide a framework which would illustrate how to adopt semantic mapping strategy instruction on teaching English to sixth grade elementary students.

\section{Hypotheses}

To probe into the effect of semantic mapping strategy instruction on the participants' vocabulary acquisition, two hypotheses were formulated and tested.

1. There are significant differences at 0.05 level between the pre-andposttest mean scores of the experimental group in the vocabulary test, in favor of the post test.

2. There are significant differences at 0.05 level between the post-test mean scores of the control group and the experimental group in the vocabulary test, in favor of the experimental group.

\section{Limitations of the Study:}

This study was limited to:

1.sixth grade elementary students at Sufan elementary School in Bisha, K.S.A. Sixth grade students were chosen as they are in a transitional grade between the elementary stage and the intermediate stage. If semantic mapping strategy instruction proves to be effective in enhancing the participants' vocabulary acquisition, it will be beneficial to adopt it in teaching vocabulary to fourth and fifth year students.

2.the second term of the academic year 2015-2016.

3.Student' s Book 'WE CAN', second term ( from unit 1to 6).

\section{Definition of Terms:}

Some terms were repeatedly used in this study. The definition of these terms is presented below.

\section{Semantic Mapping}

This term is used in this study to mean a method of vocabulary instruction that allows students to make connections between vocabulary items and other related words or words that are already known. 


\section{Vocabulary}

In this study, the term 'vocabulary' is used to mean the words or combinations of words (such as collocations, compound nouns phrasal verbs and idioms) which are explicitly and/or implicitly taught in the EFL course (WE CAN) prescribed for sixth grade elementary students in K.S.A

\section{Vocabulary Acquisition}

Vocabulary acquisition is learning and understanding new terminology to such a degree that it can be used accurately in oral and/or written communication.

\section{Elementary School}

The primary level in Saudi schools extending from grade 1 at the age of six to grade 6 at the age twelve.

\section{Review of Literature:}

This section consists of two parts. Part one 'Semantic Mapping' deals with the definitions of semantic mapping, advantages of semantic mapping strategy, and disadvantages of semantic mapping strategy. It also sheds light semantic mapping strategy instruction. Part two 'vocabulary' deals with the definition of vocabulary, importance of vocabulary, explicit versus implicit vocabulary instruction. In addition, it highlights taxonomies of vocabulary learning strategies.

\section{Part one: Semantic Mapping}

Semantic mapping is a strategy which visualizes meaning-based connections between words or concepts and other related words or concepts. It helps EFL learners to identify and recall meanings of the target words.

\section{Definition of 'Semantic Mapping'}

The term 'semantic mapping' has been defined by many researchers. For example, while Nilforoushan (2012:165) looks upon 'semantic mapping' "as a tool for discovering the conceptual relationship between vocabulary items ", Zahedi \& Abdi (2012: 2274) consider it a tool which "has the effect of bringing relationships in a text to consciousness for the purpose of 
deepening the understanding of a text and creating associative networks for words". In addition, Tateum (2007: 7) defines 'semantic mapping' as the "process for constructing visual displays of categories and their relationships." Moreover, Baleghizadeh \& Yousefpoori (2011:12) state that 'semantic mapping' is a strategy which "falls under the general category of graphic organizers and is used in different subject areas in order to help learners understand relationships and form concepts about broader topics. Avrianti (2015:97) agrees with Baleghizadeh \& Yousefpoori (2011) that semantic mapping is "one type of graphic organizers that relates with concept mapping. It is a visual strategy by graphic displaying words in categories and showing how they are related to one another.

In this study, 'semantic mapping' is used to mean a method of vocabulary instruction that allows students to make connections between vocabulary items and other related words or words that are already known. The following is a sample semantic map created by participants in the experimental group (Unit two: Life's Ups and Downs, p.15)

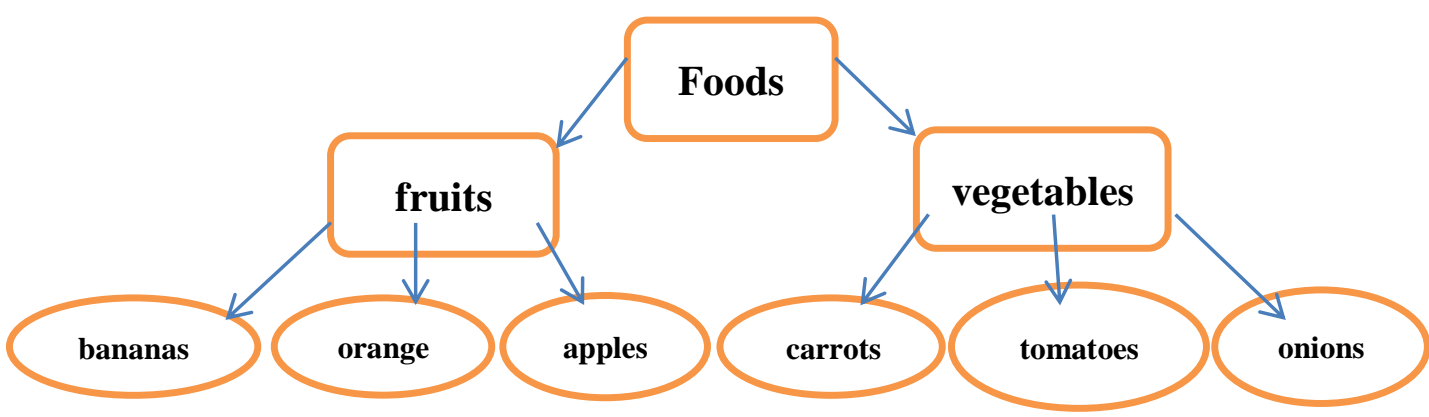

A Sample Semantic Map (Unit two: Life's Ups and Downs, p.15)

\section{Advantages of Semantic Mapping Strategy}

Review of literature about 'semantic mapping' offers a number of advantages (Barcoft, 2004: 201;Tateum ,2007:19; Zahedi and Abdi ,2012: 2274).These are:

\section{2.a. Ensuring Better Vocabulary Retention}

Semantic mapping seems to ensure better word learning and retention by enabling EFL learners to incorporate new information into their previous knowledge. It helps learners to use vocabulary items in their word repertoire to associate meaning with the new vocabulary. 
Thus, semantic mapping, as concluded by Barcoft (2004:201), positively affects learners' memory for (a) previously acquired words (b) new words recorded as known words. This was supported by Tateum (2007: 18 ) who revealed that semantic mapping in language classes involves a variety of basic memory and comprehension strategies (such as grouping, marking associations, and using visual memory of semantic maps) which associate relevant previous vocabulary knowledge to the new one.

\section{2.b. Enhancing Interaction and Collaboration}

Semantic mapping encompasses drawing webs or maps displaying relationships between words according to their use in particular texts. It is best used as a collaborative work between the teacher and the learners. It encourages student-student and teacher-student interaction and collaboration. For example, in this study, the participants were encouraged to create semantic maps in collaboration with the teacher. The teacher used to introduce several target vocabulary items, put them on maps and elaborate on them with the participants who then added other vocabulary items while studying the prescribed course (WE CAN). In addition, the participants used to work in groups to gather related words simultaneously. Moreover, while creating their maps with the teacher learners were not only encouraged to visualize words relationships, but also to categorize the target vocabulary items. Such collaborative effort triggered classroom interaction and enabled learners to share their ideas. It also enabled the participants to make sense of the studied topics.

\section{2.c. Fostering Learners' Independence and Self-confidence}

Language learning strategies ensure better learner independence and independence as they enable learners to assume responsibility for their own learning and gradually gain confidence. So is the case with semantic mapping strategy which assists learners in becoming independent, confident learners (Chamot, 2005:113). In this study, the participants were trained on developing guided semantic maps in collaboration with the teacher and peers and then were encouraged to 
create their free semantic maps while studying their course (WE CAN).

\section{2.d. Addressing Learners' Different Learning Styles}

Each learner has different areas of interest, different strengths, different weaknesses and different abilities. So, EFL teachers and educators should create an environment in which equal attention is given to all learners. Thus, only by recognizing the fact that learners are different and learn differently can EFL teachers fully encourage them to try harder and at the same time create a meaningful and enjoyable learning environment. Semantic mapping strategy helps teachers address their students' different learning styles and create a rich learning environment for all. For instance, teachers can introduce semantic maps in different forms such as squares, circles, or ovals with connecting lines, which appeal to various learning styles. In addition, semantic mapping strategy amalgamates a variety of other memory strategies such as categorizing, grouping, using imagery and associating as well as elaborating, which also appeal to various learning styles. Thus, as indicated by Zahedi and Abdi (2012: 2274), it is important for teachers to decide what kind of semantic maps they should choose to focus on based on their student's needs, learning styles, proficiency level as well as the task's requirements.

\section{2.e. Creating Meaningful Vocabulary Learning}

Meaningful learning is important for EFL learners as it helps them integrate new knowledge into their existing knowledge in their cognitive structures. Although vocabulary semantic maps are generally considered as word webs or networks, parts of these maps have hierarchical treelike structures. When vocabulary semantic maps are created in a hierarchical structure, the broader and more general vocabulary items are located at the top of the maps, with progressively narrower and more specific words arranged below them. It is this hierarchical attribute of vocabulary semantic maps which enhance meaningful vocabulary learning since new vocabulary items are subsumed under broader, more general items (Barcoft, 204:202).

\section{2.f. Overcoming Vocabulary Learning Difficulties}

Memory strategies play a vital role in vocabulary acquisition. 
According to Oxford (1990:8), memory strategies are powerful mental tools for language learners to cope with vocabulary learning difficulties as they make learning easier, faster, more enjoyable, more self-directed, more effective, and more transferable to new situations. In addition, the hierarchical and organizational nature of semantic maps help learners clarify and discriminate confusing vocabulary items.

\section{Disadvantages of Semantic Mapping Strategy}

Apart from the advantages of using semantic maps in vocabulary learning, there are some disadvantages associated with using this strategy (Baleghizadeh \& Yousefpoori (2011:13) :

\section{3.a. Shackling Learners' Imagination and Creativity}

One of the major problems with semantic mapping is that it might shackle learners' imagination or creativity if it is limited to grouping related words. Also, presenting only one fixed structure or shape of maps to the learners might hinder their creativity. In addition, the presented semantic maps might be based on some grouping procedures that are discrepant with the way learners would group the target vocabulary items. In this study, some techniques were adopted to overcome this potential problem. For example, after presenting the target vocabulary maps, the teacher used to ask learners to provide new words to be added or to change the map structure by connecting the words differently according to their perspective. Other times, the teacher asked individual learners to create their own maps for a set of words and at the end, asked them to choose the best ones.

\section{3.b. Interference among Semantically-Related Words.}

There is dispute among EFL teachers and educators about the effectiveness of presenting semantically related words using semantic maps strategy. While proponents advocate this strategy, opponents argue that the presentation of semantically related words enhances interference among them. Opponents also claim that due to "cross association and possible overloading in the short term memory," vocabulary retention might be even hindered because learning lexical sets, synonyms, opposites or free associates together also leads to 
interference (Erten \& Tekin, 2008:408).

\section{Semantic Mapping Strategy Instruction}

Learning new vocabulary is a hard and demanding task for EFL learners but they can overcome by adopting a variety of vocabulary learning strategies. Learners should be trained to use strategies appropriate for them. So, vocabulary instruction should not be confined to teaching specific vocabulary items, but rather equipping learners with the strategies they need to enhance their vocabulary acquisition. In this study, two types of semantic maps were taught to the experimental group: guided semantic maps and free semantic maps.

\section{4a.Guided Semantic Maps}

Guided semantic maps aimed to help the participants adopt semantic mapping strategy while learning vocabulary. The teacher collaborated with the learners to create these maps. The phases, proposed by Morin \& Goebel (2001:208) were carried out for teaching guided semantic mapping strategy to the experimental group. Arabic was used as a medium of instruction to ensure better understanding on the part of the participants who were sixth grade elementary learners.

Phase 1: In the first phase, the teacher described and presented explicitly the semantic mapping strategy to the learners. Then, he showed sample semantic maps as a brainstorming activity to encourage learners to discuss why, when and how to use this strategy.

Phase 2: In second phase, whether the strategy was used before, during, and after the assigned activity, the teacher wrote the central theme of the text on the board.

Phase 3: Then, the class was divided into small groups. Each group was given a central word and was invited to provide related words. The participants were encouraged to look up the words they didn't know and suggest words other than the ones in the text. The teachers moved around the class to provide help when needed. In this phase, all responses were accepted as long as they relate to the central word or concept.

Phase 4: In this phase, the teacher wrote the suggested words on the board and connected them with lines and arrows to the main word. All 
the guided semantic maps were drawn on the board so that they could be shared with all learners in the class. Also, the teacher used different colored markers at each step of semantic mapping instruction to boost learners' conceptualization and structuring of the topic and enable them to recognize the different sources of information Olson \& Gee (1991:299).

Phase 5: After creating the target semantic maps, participants in each group had to elaborate on the words they suggested, explaining to the other groups why they included them in their semantic maps and how they were related to the central word. Learners also explained the words that were not in the text and were not known by the other participants.

Phase 6: At the last phase, feedback is provided by the teacher and/or participants. Then, participants were asked to copy the maps in their notebooks. Then, participants were asked to use new vocabulary items in new contexts either in class or as homework.

\section{4.b. Free Semantic Maps}

In addition to guided semantic maps, learners were encouraged to create their own maps idependently. Learners were taught the directions proposed by Zorfass \& Gray (2016:2) for creating their free semantic maps. The directions were taught in Arabic to suit the participants who were sixth grade students.

-Find a word you don't know from the text you are reading and mark the word. Make sure the word is central to the topic.

-Draw a map/web (either on paper or a digital tool).

-Put the word in the center of the map/web.

-Pronounce the word. If possible, use an online dictionary for better pronunciation.

-Read the text around the word to find a definition of the word in addition to related words you can add to the map.

- If the definition is not in the text, use an online dictionary or online thesaurus to look up the word and find a definition.

-Look for the words and phrases that fit with the meaning. Choose pictures/images (online or from available resources) or draw pictures that fit with the meaning.

-Add these words, phrases, or images to your semantic map. 
-Read the text again, applying the meaning of the word to the text.

-Share and compare your map with your peers.

\section{Part two: Vocabulary}

Vocabulary is a necessary component of communication in the foreign language. Thus, EFL learners should acquire an adequate numbers of vocabulary items and should know how to use them accurately for communication.

\section{Definition of Vocabulary}

Vocabulary is defined in many different ways. While Afrin (2014:66) defines vocabulary as "all the words known and used by a particular person", Thuy (2013:630) looks upon vocabulary "as the words or a set of words in a language or knowledge of words regarding its forms, meanings and how to use it accurately in the context". In addition, Ghazal (2007: 84) describes vocabulary as the "building blocks of a language since they label objects, actions, ideas without which people cannot convey the intended meaning". In this study, the term 'vocabulary' is used to mean the words or combinations of words (such as collocations, compound nouns phrasal verbs and idioms) which are explicitly and/or implicitly taught in the EFL course (WE CAN) prescribed for sixth grade elementary students in K.S.A.

\section{Importance of Vocabulary (and Language Acquisition)}

Vocabulary plays a vital role in language acquisition as it constitutes an integral part of the four main language skills: listening, speaking, reading and writing. It provides much of the basis for how well EFL learners listen, speak, read, and write (Richards \&Renandya, 2002:386). Thus, if learners lack adequate vocabulary knowledge, their ability to express themselves in the foreign language will be limited. Agreeing with Richards \& Renandya, Barcroft (2004:201) defined three points that underline the importance of vocabulary in language acquisition including: (1) the relationship between vocabulary and the ability to communicate, (2) student perceptions about the relative importance of vocabulary, and (3) the critical role of vocabulary knowledge in the development of grammatical competence.

Afrin (2014:66) also identified the following reasons for encouraging learners to acquire rich vocabulary:

-It helps learners express subject matter and ideas clearly and 
accurately.

-Learners can have more prestige if their listening, speaking, reading, and writing vocabularies are adequately developed,

-Leaners can read and comprehend better if they have good vocabulary repertoire.

- Having good vocabulary repertoire ensures better opportunity for success in professional life.

- For EFL learners, appropriate level of vocabulary knowledge is necessary for successful communication to occur.

-Flexible use of vocabulary is necessary to convey intended messages.

-Vocabulary development is necessary for practicing the main four language skills: listening, speaking, reading and writing.

\section{Explicit versus Implicit Vocabulary Instruction}

Previous research about vocabulary reveals two types vocabulary instruction: explicit and implicit vocabulary instruction Morin \&Goebel

(2001: 10) and Decarrico (2001:286).

\section{3.a. Explicit Vocabulary Instruction}

Explicit vocabulary instruction encourages EFL learners to learn vocabulary items directly. It enables them to guess meanings of words from context, use dictionaries, memorizing word lists and perform other direct procedures for vocabulary learning. It also motivates learners to adopt appropriate word learning strategies. The efficiency of explicit vocabulary instruction was proved by Morin \& Goebel (2001) who conducted three experimental studies, all of which concluded that incidental vocabulary instruction is not sufficient on its own and that explicit instruction of vocabulary is both needed and beneficial. Morin and Goebel (2001: 10) also proved the effectiveness of explicit vocabulary instruction in terms of quality of word knowledge and the number of learnt words. 


\section{3.b. Implicit Vocabulary Instruction}

Unlike explicit vocabulary instruction, implicit vocabulary instruction provides learners with various activities such as intensive reading and extensive reading, which enable them to learn vocabulary items indirectly. Thus, as indicated by Decarrico (2001:286),"implicit vocabulary instruction occurs when the mind is focused elsewhere, such as understanding a text or using language for communicative purposes". This means that meanings of the new vocabulary items are acquired subconsciously and unintentionally. Accordingly, implicit vocabulary instruction takes place through multiple exposures to words in different contexts; the more learners are exposed to vocabulary items in different contexts, the more they acquire them.

Previous studies concluded that both types (explicit and implicit vocabulary instruction) are important for vocabulary acquisition since some aspects of vocabulary can be learned consciously and some other aspects can acquired incidentally For example, Barcroft (2009:97) revealed that "by getting students to intentionally learn target words during reading and informing them that they will be tested on them led to an increase in the learning of word forms compared to students who only read for meaning". Accordingly, both explicit vocabulary instruction and implicit vocabulary instruction were adopted in this study. For instance, in reading lessons, explicit vocabulary instruction was used at the pre and post reading stages by presenting the new words and their associates before reading in semantic maps form and elaborating on target vocabulary items after reading in semantic maps form. Implicit vocabulary instruction was adopted at the during reading stage.

\section{Taxonomies of Vocabulary Learning Strategies}

According to Nation (1990:16), knowing a word involves knowing its pronunciation, spelling, collocations (i.e. words it collocate with), and appropriate use. Thus, lexical competence is not confined to the ability to define a number of words but encompasses a wide range of vocabulary knowledge which can be achieved by adopting various vocabulary learning strategies. Accordingly, EFL/ESL researchers have 
proposed some taxonomies of vocabulary learning strategies. Examples of such taxonomies are presented below $\mathrm{Gu}$ and Johnson (1996) and Nation (2001).

$\mathrm{Gu}$ and Johnson (1996) classified vocabulary learning strategies into cognitive, metacognitive, memory and activation strategies. Cognitive strategies include guessing strategies, dictionary use and notetaking strategies. Guessing strategies enable EFL learners to use their background knowledge and linguistic clues of sentences to guess meanings of words. In addition, Metacognitive strategies involve selective attention and self-initiation strategies. While learners adopting selective attention strategies know which words are important for them to learn and which ones are essential for adequate text comprehension, learners using self-initiation strategies employ various strategies for clarifying word meanings. Memory strategies include rehearsal strategies which encompass word lists and repetition and encoding strategies such as association, imagery, visual, auditory, semantic, and contextual encoding as well as word-structure (prefixes, stems, and suffixes...etc.). Activation strategies involve the strategies which enable learners to use new vocabulary items in different contexts.

In a more recent classification, Nation (2001: 222) provided taxonomy of vocabulary learning strategies which included three general strategies of 'planning', 'source' and 'processes', each of which is divided into a subset of strategies. 'Planning' strategies involves determining when, where, how and why to focus attention on specific vocabulary items. Examples of planning strategies are choosing vocabulary items and aspects of word knowledge. 'Source' strategies consist of getting information from different sources about vocabulary items. This information can come from the word form itself, word contexts, reference sources like dictionaries or glossaries and analogies and connections with other languages. 'Process' strategies include establishing word knowledge through noticing, retrieving and generating strategies. Noticing means seeing the vocabulary items to be learned. Strategies at this level contain putting the word in a vocabulary note-book or list; putting the word on a word card and orally and visually repeating the word. Retrieval means recalling vocabulary items 
in the same way they were originally stored. Generating strategies comprise "attaching new aspects of knowledge to what is known through instantiation (i.e., visualizing examples of words), word analysis, semantic mapping and using scales and grids" (Nation, 2001: 222). Generating strategies include rule-driven generations about vocabulary items such as using words in different contexts through the four skills and creating contexts, collocations and sentences containing the new words.

In general, although the taxonomies cited above may slightly differ in terms of the strategies they categorize, they all provide a list of vocabulary learning strategies which all attempt to enhance learners' vocabulary acquisition. In addition, these strategies ensure better learner involvement and participation in vocabulary learning; they encourage learners to play an active role the vocabulary learning process (guessing strategies, skillful dictionary use, note-taking strategies, planning, source and processes). Accordingly, since vocabulary acquisition cannot occur within the class time limits, EFL learners should be equipped with a number of the abovementioned strategies which will enable them to deal with vocabulary items on their own and as a result guarantee better vocabulary acquisition.

\section{Methodology}

This section deals with the design of the study, participants, instruments and procedures.

\section{Design}

The design of the study is quasi-experimental design consisting of two groups: a control group $(\mathrm{N}=26)$ and an experimental group $(\mathrm{N}=26)$. At the beginning of the second week of the second term of the academic year 2015-2016, the pre-test (The Vocabulary Test) was administered to the two groups. Then, the experimental group was taught the coursebook 'WE CAN' using semantic mapping strategy, while the control group was taught the same course-book in the traditional method. The duration of the experiment was fourteen weeks, four forty-five minute periods a week. At the end of the experiment, both groups were post- 
tested using the same vocabulary test.

\section{Participants}

Two classes (Fifty two sixth-grade elementary students) from Sufan elementary School in Bisha participated in this study. One of the classes (class $6 / \mathrm{B})$ was assigned to the experimental group $(\mathrm{N}=26)$ and the other (class 6/A) was assigned to the control group ( $\mathrm{N}=26)$.

\section{Instruments}

To collect data, a vocabulary test was prepared and used as a preposttest. The test was designed to measure students' vocabulary acquisition in the prescribed course 'WE CAN'. The test consisted of three dimensions with thirty items (Appendix One).

\section{Test Validity}

Two methods were used for determining the test validity, namely, face validity and intrinsic validity.

\section{a) Face Validity}

The vocabulary test was submitted to a jury of three college staff members and five EFL teachers to state how far the test items measure the skills they were intended to measure and make the necessary modifications (Appendix two). Based on the jury members' remarks, items of questionable validity were revised or deleted. In addition, other new items were added.

\section{b)Intrinsic Validity}

The test intrinsic validity was determined through the square root of the test reliability coefficient (El-Said, 1979:553). The test reliability coefficient was $\sqrt{0.810}$. The intrinsic validity is 0.90 . Thus, the test was valid.

\section{Test Reliability}

The test-retest reliability was adopted. The test was administered to forty-five sixth-grade elementary students at Sufan Primary School by the end of the first term of the academic year 2015-2016 with an interval of two weeks. Pearson Product-moment correlation coefficient was calculated (Brown, 1996:155). It was 0.810 Thus, the calculated correlation coefficient is larger than the critical value $(0.3218)$. This 
means that the calculated correlation coefficient is statistically significant (Brown, 1996:163).

\section{Procedures}

Before the experiment, the vocabulary test was designed. Then, the test validity and reliability were identified by the end of the first term of the academic year 2015-2016. At the beginning of the experiment (the second week of the second term of the academic year 2015-2016), the participants were introduced to the purposes of the study. Then, they were assigned either to the control group $(\mathrm{N}=26)$ or the experimental group $(\mathrm{N}=26)$. Afterwards, the teacher explained to each group what to do during the experiment. Next, the pre-test (The Vocabulary Test) was administered to the two groups.

During the experiment which lasted for fourteen weeks, the teacher, who had ten years of teaching experience, taught the prescribed course-book 'WE CAN' applying the semantic mapping strategy with the experimental group whereas the control group received traditional instruction.

At the end of the experiment, the post-test (The Vocabulary Test) was administered to the two groups. Finally, based on the statistical analysis of the obtained data, results were discussed and recommendations were made. 


\section{Materials \\ 1. The General Goals of Teaching English Language for the Elementary Stage}

By the end of the course, learners were expected to be able to: 1.learn the basics of the English language that would form foundation for its mastery in the future

2. use the basic structures of English sentences.

3. learn the core vocabulary assigned for this stage.

4. listen and understand simple English language.

5. express themselves orally using simple English language.

6. read and understand simple written English language materials.

7. write simple guided sentences in English language.

8. appreciate the importance of English language as an international language of communication, for introducing Islam, the Islamic nation's culture and the cultural achievements of Muslims to other nations. 9. appreciate the importance of English language as an international language of communication to benefit from the achievements of other cultures in accordance with Islam.

\section{The Course Content}

The course-book of the second term includes six units. The topics of the units are: Fun on the Weekend, Life's Ups and Downs, My School is Cool, A Healthy Life, Hanging Out in Town and My Dream Vacation.

\section{Results and Discussion}

In this section, results will be presented along with a discussion based on the statistical analysis of the collected data.

To make sure that there were no significant differences between the experimental group and the control group at the beginning of the experiment, Independent Samples T-test was used to compare the mean scores of the two groups on the pre-test. Table (1) shows means, standard deviations and t-values of the two groups. 
Table (1) Means, Standard Deviations and T-Values of the Experimental Group and the Control Group on the Pre-Vocabulary Test.

\begin{tabular}{|c|c|c|c|c|c|c|c|}
\hline Dimension & Group & No. & Mean & S.D. & T-Values & df & Sig. \\
\hline One & $\begin{array}{c}\text { Control } \\
\text { Experimental }\end{array}$ & $\begin{array}{l}26 \\
26\end{array}$ & $\begin{array}{l}1.8846 \\
2.0769\end{array}$ & $\begin{array}{l}1.27521 \\
1.01678\end{array}$ & 0.601 & 50 & N.S. \\
\hline two & $\begin{array}{c}\text { Control } \\
\text { Experimental }\end{array}$ & $\begin{array}{l}26 \\
26\end{array}$ & $\begin{array}{l}2.4231 \\
2.4615\end{array}$ & $\begin{array}{l}1.06482 \\
1.17408\end{array}$ & 0.124 & 50 & N.S. \\
\hline Three & $\begin{array}{c}\text { Control } \\
\text { Experimental }\end{array}$ & $\begin{array}{l}26 \\
26\end{array}$ & $\begin{array}{l}2.4231 \\
2.5769\end{array}$ & $\begin{array}{l}1.06482 \\
1.02657\end{array}$ & 0.530 & 50 & N.S. \\
\hline Total & $\begin{array}{c}\text { Control } \\
\text { Experimental }\end{array}$ & $\begin{array}{l}26 \\
26\end{array}$ & $\begin{array}{l}6.7308 \\
7.1154\end{array}$ & $\begin{array}{l}2.35894 \\
2.17857\end{array}$ & 0.611 & 50 & N.S. \\
\hline
\end{tabular}

Results in table (1) show that there were no significant differences between the pre-test mean scores of the control group and the experimental group at the beginning of the experiment. This indicates that the two groups were homogeneous at the beginning of the experiment. Results also reveal that the mean scores of the two groups were very low. This, as concluded by Al-Mohanna (2010:72), may be attributed to the traditional vocabulary teaching methods which encouraged learners to memorize words in vocabulary lists, not in context. So, they did not acquire vocabulary items in a way which enabled them to store and retrieve these words for use in new situations. Another interpretation is that students had come from the mid-term vacation in which they might not have practiced any language activities.

In response to the first research question, "What is the effect of semantic mapping strategy instruction on sixth grade elementary students' vocabulary acquisition?, Paired Samples T-test was used. Table (2) shows means, standard deviations and t-values of the experimental group in the pre-and-posttest. 
Table (2) Means, Standard Deviations and T-Values of the Experimental Group in the Pre-and-Post Test.

\begin{tabular}{|c|c|c|c|c|c|c|c|}
\hline \multirow{2}{*}{ Dimension } & \multicolumn{2}{|c|}{ Mean } & \multicolumn{2}{c|}{ S.D. } & \multicolumn{1}{c|}{ T- } & df & Sig. \\
\cline { 2 - 7 } & Pre & Post & Pre & Post & & \\
\hline One & 2.0769 & 5.8846 & 1.01678 & 1.58308 & 12.469 & 25 & .000 \\
\hline Two & 2.4615 & 6.6923 & 1.17408 & 1.04954 & 18.239 & 25 & .000 \\
\hline Three & 2.5769 & 6.5769 & 1.02657 & 1.17211 & 16.737 & 25 & .000 \\
\hline Total & 7.1154 & 19.1154 & 2.17857 & 1.17211 & 19.187 & 25 & .000 \\
\hline
\end{tabular}

Results in table (2) show that, in spite of the low performance of the participants in the pretest, there were significant differences at 0.01 level between the pre-and-post mean scores of the experimental group in the three dimensions of the vocabulary test as well as the whole test, in favor of the post-test. Thus, the first hypothesis stating that " there are significant differences at 0.05 level between the pre-and-posttest mean scores of the experimental group in the vocabulary test, in favor of the post-test", was verified. These results mean that semantic mapping strategy instruction led to significant improvement in the participants' vocabulary acquisition. This improvement may be due to the cognitive feature of semantic mapping. According to Tateum (2007: 19), the relationships among the words account for this cognitive feature of semantic mapping. These results agree with the conclusions of Shapiro and Waters (2005) who concluded that increasing the cognitive effort equals an enhancement in vocabulary retention. They are also supported by Morin and Goebel (2001:10) who revealed that semantic mapping engages a very deep level of cognition which enables learners to organize their cognitive mental frameworks into more powerful integrated structures. Accordingly, as concluded by Chiou (2008: 375), adopting a semantic mapping strategy instruction can significantly improve EFL learners' vocabulary acquisition, compared to using the traditional teaching method.

Another plausible reason why semantic mapping strategy instruction boosted the participants' vocabulary acquisition is that it triggered classroom interaction and collaboration which are important 
aspects of effective learning environment. The participants used to collaborate with the teacher and their classmates to develop vocabulary semantic maps. Also, the teacher used to introduce several target vocabulary items, put them on maps and elaborate on them with the participants. In addition, the participants used to work in groups to find related words simultaneously. Such collaborative effort created a scaffolding learning environment which had positive effects on their vocabulary acquisition.

A third possible interpretation is that, since semantic mapping has different structures (squares, circles, or ovals ...etc.), it appealed to the participants' various learning abilities. It enabled them to access the vocabulary items at their own pace and offered various map structures appealing to a broad range of learning abilities. Accordingly, by addressing the participants' different abilities, semantic mapping strategy encouraged them to try harder and at the same time made the learning environment as meaningful and enjoyable as possible for them. Thus, semantic mapping strategy enhanced the participants' motivation and created more positive attitudes towards vocabulary acquisition. These results agree with previous conclusions about the positive effects of semantic mapping strategy on vocabulary acquisition (Keshavarz et al., 2006:149;Abdollahzadeh \& Amiri-Vardani (2009:1; Baleghizadeh \& Yousefpoori ,2011:15 ; Nilforoushan , 2012:165;Abbasian \& Arianezhad , 2013: 139; Jang, 2014:25; Afrin, 2014:65 and Avrianti ,2015:95).

To answer the second research question: "Which is more effective, the traditional method or semantic mapping strategy instruction, in enhancing students' vocabulary acquisition?, results in table (3) show that there were significant differences at 0.001 level between the posttest mean scores of the control group and the experimental group in the vocabulary test, in favor of the experimental group. Table (3) shows means, standard deviations and t-values of the two groups in the post test. 
Table (3): Means, Standard Deviations and T-Values of the Two Groups in the Post Test.

\begin{tabular}{|c|c|c|c|c|c|c|c|}
\hline Dimension & Group & No. & Mean & S.D. & $\begin{array}{c}\text { T- } \\
\text { Values }\end{array}$ & df & Sig. \\
\hline One & $\begin{array}{c}\text { Control } \\
\text { Experimental }\end{array}$ & $\begin{array}{l}26 \\
26\end{array}$ & $\begin{array}{l}2.5385 \\
5.8846\end{array}$ & $\begin{array}{l}1.20767 \\
1.58308\end{array}$ & 8.569 & 50 & 0.000 \\
\hline Two & $\begin{array}{c}\text { Control } \\
\text { Experimental }\end{array}$ & $\begin{array}{l}26 \\
26\end{array}$ & $\begin{array}{l}2.9615 \\
6.6923\end{array}$ & $\begin{array}{l}1.28002 \\
1.04954\end{array}$ & 11.492 & 50 & 0.000 \\
\hline Three & $\begin{array}{c}\text { Control } \\
\text { Experimental }\end{array}$ & $\begin{array}{l}26 \\
26\end{array}$ & $\begin{array}{l}3.2692 \\
6.5769\end{array}$ & $\begin{array}{l}0.87442 \\
1.17211\end{array}$ & 11.533 & 50 & 0.000 \\
\hline Total & $\begin{array}{c}\text { Control } \\
\text { Experimental }\end{array}$ & $\begin{array}{l}26 \\
26\end{array}$ & $\begin{array}{c}8.7692 \\
19.1154\end{array}$ & $\begin{array}{l}2.30318 \\
2.88897\end{array}$ & 14.279 & 50 & 0.000 \\
\hline
\end{tabular}

Results in table (3) reveal that there were significant differences at 0.01 level between the post-test mean scores of the control group and the experimental group in the three dimensions of the vocabulary test as well as the test as a whole, in favor of the experimental group. This means that semantic mapping strategy instruction was more profitable to the participants than the traditional method. These results verify the second hypothesis stating that "There are significant differences at 0.05 level between the post-test mean scores of the control group and the experimental group in the vocabulary test, in favor of the experimental group." These results may be attributed to the fact that compared the control group, the participants of the experimental group were trained and encouraged to use semantic mapping strategy which appealed to all the participants' different learning styles. The teacher used to introduce semantic maps in different forms such as squares, circles, or ovals ...etc. This created an environment in which equal attention is given to all the participants and encouraged them to try harder and at the same time created a meaningful and enjoyable learning environment. These results are commensurate with conclusions of Johnson (2007: 20) that 
addressing learners' different learning styles and abilities ensures better learning.

In addition, semantic mapping strategy encompasses a variety of other memory strategies such as categorizing, grouping, using imagery and associating as well as elaborating. Such strategies helped the participants to categorize words and distinguish one word from another. It also enabled the participants to visualize how word meanings can be categorized. Thus, as indicated by Hsiao and Oxford (2002: 371) semantic mapping strategy aided "learners in moving information to long-term memory for storage purposes and retrieving it from long-term when needed for use." These results are congruent with the conclusion of Oxford's (1990:37) that semantic mapping strategy helped learners to store and retrieve new information and thus, enabled them overcome the problem of remembering large amounts of vocabulary necessary to achieve fluency.

\section{Conclusion}

The present study sought to investigate the effect of semantic mapping strategy instruction on EFL sixth-grade elementary students' vocabulary acquisition. Results are encouraging as far as the effect of semantic mapping strategy instruction on the participants' vocabulary acquisition is concerned. Results also revealed that semantic mapping strategy was effective in enhancing the participants' vocabulary acquisition. In addition, compared to traditional instruction, semantic mapping strategy instruction was more effective in improving the participants' vocabulary acquisition. The superiority of semantic mapping strategy instruction over traditional instruction, theoretically, highlights the beneficial role of such a strategy in teaching vocabulary to EFL elementary stage students and implies that, pedagogically, semantic mapping strategy instruction is a better choice for EFL teachers at the primary stage. These results substantiate the importance of integrating semantic mapping strategy instruction into the EFL courses as it proved to be conductive to better vocabulary acquisition through its cognitive features which enabled the participants to move their vocabulary knowledge to the long-term memory for storage purposes and retrieving it from long-term as needed for use. In addition, it enabled the participants to organize vocabulary items in hierarchical 
map structures in which the broader and more general vocabulary items are located at the top of the maps, with progressively narrower and more specific words arranged below them. This hierarchical feature of semantic mapping strategy enhanced meaningful vocabulary learning which improved vocabulary acquisition among the participants of the experimental group.

\section{Recommendations}

Based on the results of the study, the following recommendations are made:

\section{EFL teachers should:}

a. be encouraged to adopt semantic mapping strategy on teaching English to sixth grade elementary students.

b. be trained to use semantic mapping strategy on teaching English at primary stage.

c. empower primary stage students by creating learner-centered environment in which they can create their own semantic maps.

d. encourage all forms of semantic maps (squares, circles, ovals ...etc.).

2. Semantic mapping strategy should be integrated into the teaching strategies proposed in The Teacher's Book.

3. EFL primary stage students should have a clear idea of why they use semantic mapping strategy, what they use it for and how they use it.

\section{Suggestions for Further Research}

-Future research can investigate the effect of semantic mapping strategy instruction on EFL learners' vocabulary acquisition at other stages (intermediate and secondary stages).

-Future research can investigate the effect of semantic mapping strategy instruction on EFL learners' listening, speaking, reading and writing skills.

-It is possible to investigate the effect of semantic mapping strategy instruction on EFL learners' attitudes towards the prescribed course (WE CAN).

-Since this study was conducted on male students and it is likely that male and female students learn better through different teaching 
methods, the present study needs to be replicated with female students.

-Future research studies can direct due attention to investigating the effect semantic mapping strategy instruction on EFL teachers' attitudes towards the teaching profession.

\section{References}

-Abbasian, G \& Arianezhad, B(2013). In Defense of a Hybrid Model for EFL Vocabulary Instruction, Journal of Language Teaching and Research, 4(1), 139-148.

-Abdollahzadeh \& Amiri (2009). The effect of semantic mapping as a vocabulary instruction technique on EFL learners with different perceptual learning styles. The Journal of Applied Linguistics, 2(1), 128.

-Afrin ,N.(2014). Vocabulary Teaching in the EFL Classroom: Some Methods to Accelerate Learner's Knowledge by Facilitator's Observation, International Journal of English Language, Literature and Translation Studies, 1(4),65-69.

-Agustina, Y., Ngadiso, \& Rochsantiningsih, D. (2013). The effectiveness of semantic mapping to teach reading viewed From Students, English Teaching, 1(1), 23-36

-Alamri A.A. (2008). An Evaluation of the Sixth Grade English Language. Unpublished M. A. Thesis, College of Arts, King Saud University -Alharbi, H. A. (2015).Improving Students' English Speaking Proficiency in Saudi Public Schools, International Journal of Instruction, 8(1),105116.

-Alhaisoni, M. M (2013) Teaching English in Saudi Arabia: Prospects and Challenges, Academic Research International, 4, (2), 112-118

-Alharbi, A. (2015). A descriptive-evaluative Study of a Saudi EFL textbook Series. Cogent Education, 2 (1), 1-26 (http://dx.doi.org/10.1080/2331186X.2015.1079946)

-Al-Jarf, R.(2006). Making Connections in Vocabulary Instruction. Paper Presented at the 2nd ClaSIC Conference. Singapore. 7-9 December 2006. 
-Alqahtani ,S. M.(2009). The Role of Using Reading Stories Technique on Teaching English Vocabulary for EFL Learners (Elementary Stage) in Saudi Arabia. M.A. Thesis, College of Languages and Translation, Imam Muhammad Ibn Saud Islamic University

-Aljuhaish,S. F.(2015).A Critique on Teaching English Curriculum as a Second Language in Grade Six of Primary Schools in Saudi Arabia, International Journal of Novel Research in Education and Learning, 2 (3), 33-42.

-AlMalihi, J. F.(2015). Saudi EFL Teachers' Readiness and Perceptions of Young Learners Teaching at Elementary Schools, English Language Teaching, 8, (2), 86-100.

-Al-Nasser, A. S. (2015). Problems of English Language Acquisition in

Saudi Arabia: An Exploratory-cum-remedial Study, Theory and Practice in Language Studies, 5(8) 1612-1619(DOI:

http://dx.doi.org/10.17507/tpls.0508.10).

-Alresheed, S.(2012). Exploring the Nature of the Saudi English Teachers' Beliefs and Attitudes toward EFL and its Effect on their Teaching Practice. The 6th Saudi Scientific International Conference, London, 11th -14th October 2012.

-Alshammari, M. M. (2011). The use of the Mother Tongue in Saudi EFL

Classrooms. Journal of International Educational Research, 7(4) 95102.

-Avrianti,N.(2015) Improving Students Reading Comprehension by using Semantic Mapping in Pre-reading: A Classroom Action Research to the Tenth Grade Students of a Senior High School in Mempawah, WKS:

Studies on English Language and Education, 2 (1), 95-121.

-Baleghizadeh, S. \& Yousefpoori M, (2011). Enhancing Vocabulary Retention through Semantic Mapping: A Single-Subject Study, The International Journal - Language Society and Culture,32, 11-16

-Barcroft, J. (2004). Second Language Vocabulary Acquisition: A Lexical Input Processing Approach. Foreign Language Annals 37(2) , 200-209. -Bromley, K. (2007). Nine Things every Teacher Should Know about Words and Vocabulary Instruction. Journal of Adolescent \& Adult Literacy, 50(7) 528-537. 
-Brown, A. (1996). The Effect of Rater variable in the development of an occupation-specific Language Performance Test. Language Testing, 12(1), 1-15.

- Chamot ,A. U. (2005) Language Learning Strategy Instruction: Currunt Issues and Rearch. Annual Review of Applied Linguistics, 25, 112-130. -Chiou, C.(2008). The effect of Concept Mapping on Students' Learning Achievements and Interests. Innovations in Education and Teaching International,45 (4),375-387(DOI:10.1080/14703290802377240) -Decarrico, J. S. (2001). Vocabulary Learning and Teaching. In M. CelceMurcia (Ed.), Teaching English as a Second or Foreign Language, (pp. 285-299), Boston: Heinle \& Heinle.

-El-Said, F.E. (1979).Statistical Psychology and Measuring the Human Mental Mind (3rd ed.).Cairo: Dar El-Fekr El-Araby (in Arabic). -Elyas, T., \& Picard, M. (2010). Saudi Arabian educational history: Impacts on English language teaching. Education, Business and Society: Contemporary Middle Eastern Issues, 3(2), 136-145. -Erten,I,H. \& Tekin,M.(2008). Effects on Vocabulary Acquisition of Presenting New Words in Semantic Sets versus Semantically Unrelated Sets, System, 36(3), 407-422

-Ghazal, L. (2007). Learning Vocabulary in EFL Contexts through Vocabulary Learning Strategies. Novitas-ROYAL, 1(2), 84-91.

-Hansen,K.,M.(2009). Vocabulary Instruction, Reading Comprehension, and Student Retention: A Review of Literature. M.A. Thesis, Northern Michigan University.

-Hsiao, T.Y., \& Oxford, R.L. (2002). Comparing Theories of Language Learning Strategies: A confirmatory Factor Analysis. The modern Language Journal, 86 (3), 368-383 (DOI: 10.1111/1540-4781.00155).

-Jang,H. (2014).The Effects of Semantic Clustering on EFL Young Learners' Vocabulary Learning, English Teaching, 69 (3), 25-47 Johnson, M. (2007).An Extended Literature Review: The Effect of Multiple Intelligences on Elementary Student Performance. M. A. Thesis School of Education Dominican University of California.

-Keshavarz, M.H., Ataei, M.R., \& Mohammadi.S. (2006). The effect of Semantic Mapping Strategy Instruction on Vocabulary Learning of Intermediate EFL Students. Journal of Faculty of Letters and Humanities, 49(198), 149-176 
-Khan,I., A.(2011) Learning Difficulties in English: Diagnosis and Pedagogy in Saudi Arabia, Educational Research 2 (7), 1248-1257. -Khan,S. M.(2016).The Impact of Native Language Use on Second Language Vocabulary Learning by Saudi EFL Students. English Language Teaching, 9 (5), 134-140.

-Morin, R., \& Goebel, J. (2001). Basic vocabulary instruction: teaching strategies or teaching words? Foreign Language Annals, 34 (1) 8-17.

-Mudawi, G. H. H. (2015). Using Rhymes and Songs for Teaching Core Vocabulary to Elementary School Students. ELT Voices, 5 (1), 51-62.

-Nation, P. (1990). Teaching and Learning Vocabulary. New York: Newbury House.

-Nation, I.S.P. (2001). Learning vocabulary in another language. Cambridge: Cambridge University Press.

-Nilforoushan, S. (2012). The Effect of Teaching Vocabulary through

Semantic Mapping on EFL Learners' Awareness of the Affective Dimensions of Deep Vocabulary Knowledge. English Language Teaching, 5 (10), 164-172.

-Olson, M. W., \& Gee, T. C. (1991). Content Reading Instruction in the Primary Grades: Perceptions and Strategies. The Reading Teacher, 45, (4), 298-307.

-Oxford, R. L. (1990).Language Learning Strategies: What every teacher should know. Boston: Heinle and Heinle Publishers.

-Richards, J. \& Renandya, W. (2002). Methodology in Language

Teaching: An Anthology of Current Practice. Cambridge: Cambridge University Press.

-Shapiro, A. M., \& Waters, D., L. (2005). An Investigation of the Cognitive Processes Underlying the Key-word Method of Foreign Vocabulary Learning. Language Teaching Research, 9 (2), 129-146.

-Tateum, S. (2007). A Case Study of the Implementation of Semantic Mapping as a Pre-teaching Vocabulary Activity to $2^{\text {nd }}$-Year English Major Students at Lampang Rajabhat University. M. A. in Teaching English as a Foreign Language. Language Institute, Thammasat University, Bangkok, Thailand. 
-Thuy, N,N. (2013). The Effects of Semantic Mapping on Vocabulary Memorizing, Proceedings of the $3^{\text {rd }}$ International Conference on Foreign Language Learning and Teaching , Bangkok , Tailand (15 16 March 2013).

-Zahedi, Y. \& Abdi, M. (2012).The Effect of Semantic Mapping Strategy on EFL Learners' Vocabulary Learning, Procedia-Social and

Behavioral Sciences, 69(24), 2273-2280

-Zorfass, J. \& Gray, T. (2016). Connecting Word Meanings through

Semantic Mapping. Retrieved from

http://www.readingrockets.org/article/connecting-word-meaningsthrough-semantic-mapping, on July 22, 2016 


\section{ملخـص الدراســة}

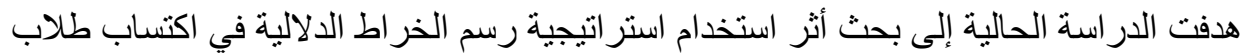

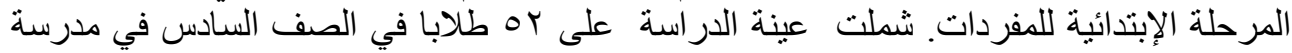

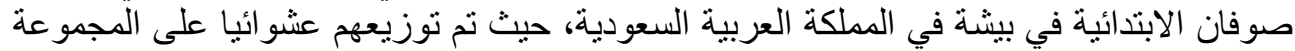

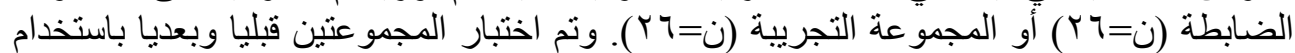

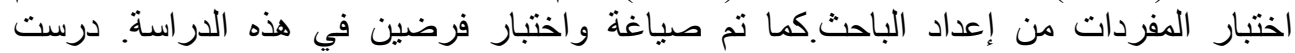

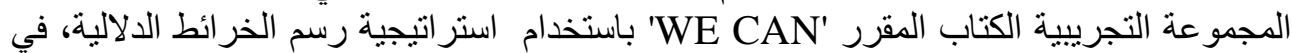
حين درست المجموعة الضابطة نفس المقرر بالطريقة التقليدية.

\section{أظهرت النتائج التي تم الحصول عليها من استخدام اختبار(ت ) :}

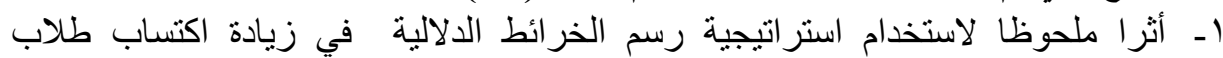

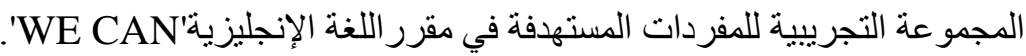

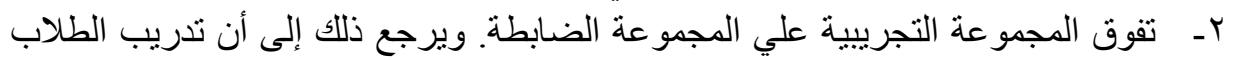

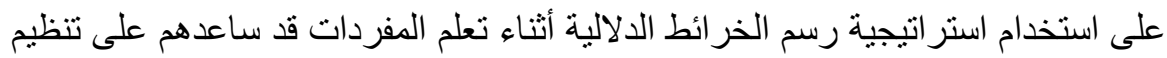

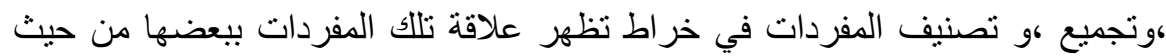

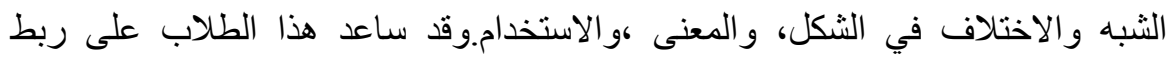

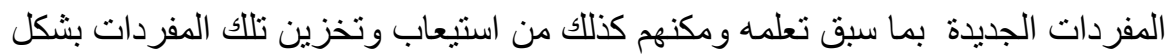

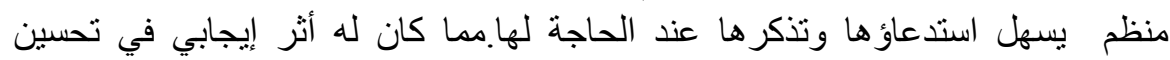
اكتساب طلاب المجمو عة التجريبية للمفردات.

\section{وفى ضوء النتائج السابقة تضمنت الاراسة التوصيات التالية:}

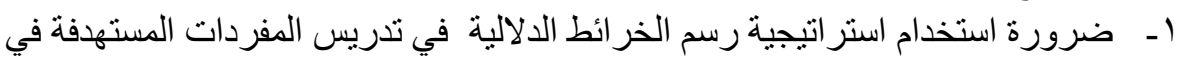

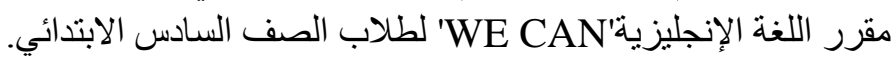

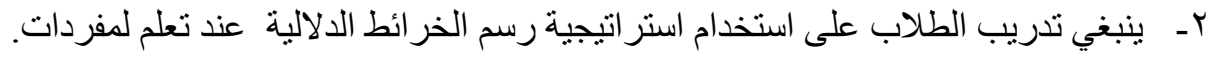

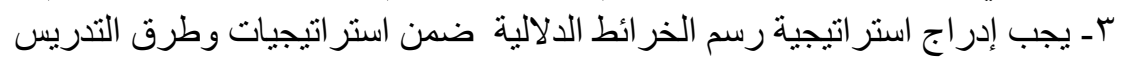
المقترحة في الكتاب المقرر.

ع - يجب أن يكون لدى طلاب المرحلة الابتدائية فكرة و اضحة عن سبب ،وتوقيت ، ولئ ، وكيفية استخدام استر اتيجية رسم الخر ائط الدلالية. هـ و ون الضروري استخدام أشكال متتو عة الخر ائط الدلالية (المربعات و الدو ائر والأشكال البيضاوية ... الخ.) لتناسب قدر اتخ ات الطلاب المختلفة.

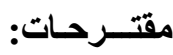
1 - يمكن إجر اء دراسات مستقبلية تبحث تأثير استخدام استر اتيجية رسم الخر ائط الدلالية في لمي اكتساب الطالبات للمفردات. 
r- يمكن لدر اسة مستقبلية بحث أثر استخدام استر اتيجية رسم الخر ائط الدلالية في تحسين

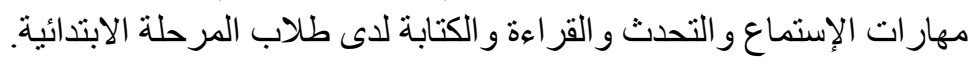

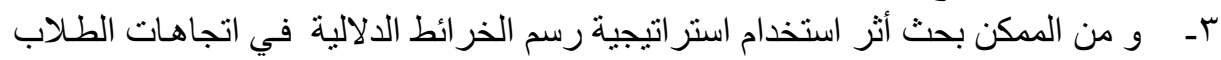
نحو تعلم المفردات.

ع - هنالك حاجة لتكر ار الدراسة مع طلاب في مر احل أخرى لمعرفة أثر استخدام استر اتيجية

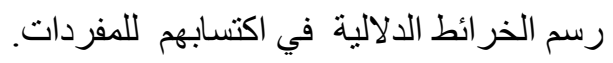

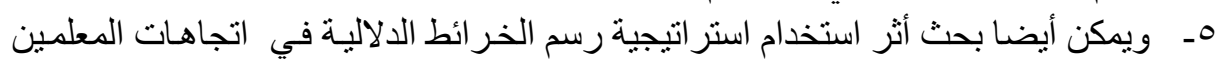
نحو مهنة التدريس. 